\title{
Severe airflow obstruction in a patient with ulcerative colitis and toxic epidermal necrolysis: A case report
}

\author{
SHIJIMA TAGUCHI ${ }^{1}$, JUNICHI FURUTA ${ }^{2}$, GEN OHARA $^{3}$, KATSUNORI KAGOHASHI $^{3}$ and HIROAKI SATOH ${ }^{3}$ \\ ${ }^{1}$ Division of Dermatology, Mito Medical Center, University of Tsukuba, Mito, Ibaraki 310-0015; ${ }^{2}$ Department of Dermatology, \\ Faculty of Medicine, University of Tsukuba, Tsukuba, Ibaraki 305-8575; ${ }^{3}$ Division of Respiratory Medicine, \\ Mito Medical Center, University of Tsukuba, Mito, Ibaraki 310-0015, Japan
}

Received May 31, 2014; Accepted January 29, 2015

DOI: $10.3892 /$ etm.2015.2307

\begin{abstract}
Bronchiolitis is a rare condition mainly affecting the intralobular conducting and transitional small airways. The present study describes a case of severe airflow limitation in a patient with ulcerative colitis who developed toxic epidermal necrolysis following mesalazine therapy. Forced expiratory volume in one second was decreased and a flow-volume curve showed airflow limitation, but the single-breath diffusing capacity of the lung for carbon monoxide $\left(\mathrm{DL}_{\mathrm{CO}}\right)$ and $\mathrm{DL}_{\mathrm{CO}}$ divided by alveolar volume $\left(\mathrm{DL}_{\mathrm{CO}} / \mathrm{VA}\right)$ were not decreased. This rare clinical condition should be considered as a differential diagnosis for subjects presenting with sub-acutely developed airflow obstruction if the findings in chest computed tomography scans demonstrate hyperinflation but few low-attenuation areas. Relatively well-preserved $\mathrm{DL}_{\mathrm{CO}}$ and $\mathrm{DL}_{\mathrm{CO}} / \mathrm{VA}$ provide a clue to establishing the correct diagnosis.
\end{abstract}

\section{Introduction}

Obstructive bronchiolitis $(\mathrm{OB})$ is a rare disease and affects small airways of the lung and is associated with restriction of the airways (1). OB must be considered as a potential diagnosis in patients with obstructive respiratory impairment, the most common symptom of which is dyspnea (1). This inflammatory process is associated with various conditions, including ulcerative colitis (UC) and toxic epidermal necrolysis (TEN). $\mathrm{UC}$ is a chronic relapsing inflammatory bowel disease of uncertain etiology. UC may occur at any age, but is most commonly diagnosed in late adolescence or early adulthood (2). The incidence of UC has increased worldwide over recent decades, particularly in developing nations (2). Typical

Correspondence to: Professor Hiroaki Satoh, Division of Respiratory Medicine, Mito Medical Center, University of Tsukuba, Miya-machi 3-2-7, Mito, Ibaraki 310-0015, Japan

E-mail: hirosato@md.tsukuba.ac.jp

Key words: airflow obstruction, ulcerative colitis, mesalazine, toxic epidermal necrolysis, obstructive bronchiolitis symptoms of UC include, bloody diarrhea, abdominal pain, urinary urgency and tenesmus (2). TEN is acute drug-induced condition associated with severe blistering, skin peeling and multi-organ damage, and is classed in the same spectrum of diseases as Stevens-Johnson syndrome $(3,4)$. TEN symptoms typically resemble severe scalding, with $\geq 30 \%$ top layer of skin detaching from the lower dermis (3). OB must be considered as a differential diagnosis in patients with obstructive respiratory impairment (4). In the case reported in the present study a patient with ulcerative colitis (UC), who developed toxic epidermal necrolysis (TEN) (5) following mesalazine therapy, presented with severe airflow limitation.

\section{Case report}

A 53-year-old male was received at the Mito Medical Center (Mito, Japan) with a two-month history of exertional dyspnea, which was not accompanied by a dry cough, fever, chill or chest pain. There was no history of antecedent respiratory tract infection. The patient had a 15-pack-year smoking history, having stopped 20 years previously, and no allergies. There was no recognized history of exposure to fumes or mineral dusts. The patient had been diagnosed as having UC 25 years previously and was given mesalazine therapy, since therapy with prednisolone had not led to any improvement in the UC. Following an increase in the dose of mesalazine to $2,250 \mathrm{mg} /$ day, the patient developed a high fever $\left(>38^{\circ} \mathrm{C}\right)$ and a large number of red papules and erythemas. The eruptions rapidly spread to the whole body and changed to erythroderma in one week. The eruptions additionally caused blistering, epidermolysis and erosion of $>10 \%$ of the body's surfaces a few days later. No findings suggested staphylococcal scalded skin syndrome. Based on the skin symptoms and clinical course, the patient was diagnosed with TEN due to the mesalazine. The patient received several courses of steroid pulse therapy with methylprednisolone and plasma exchange therapy. The patient recovered from the TEN as a result of these intensive therapies, although scars and pigmentation in the trunk and extremities remained. Informed consent was obtained from the patient.

On admission, the respiratory rate of the patient was 18 beats/min and his breath sound was diminished, without any expiratory rhonchi. Clubbing was absent. The forced 


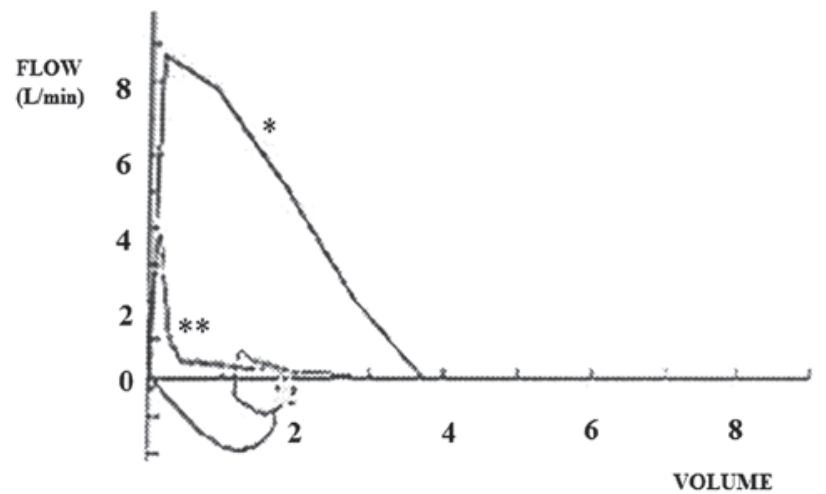

(L)

Figure 1. Flow-volume curve at the time of presentation to the hospital with dyspnea on effort. "Predicted curve; ${ }^{* *}$ measured curve.

A

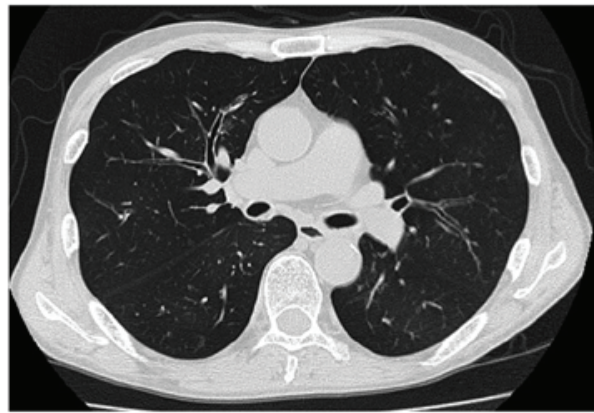

B

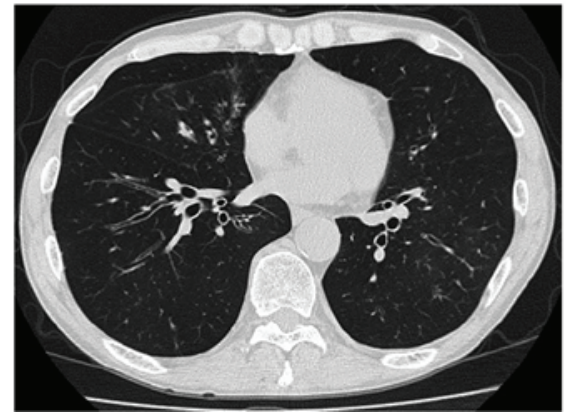

Figure 2. Slices (A) and (B) of chest computed tomography scan display bronchiectasis and thickening of the walls of the central bronchi in both lungs.

expiratory volume in one second $\left(\mathrm{FEV}_{1.0}\right)$ was 0.77 liters (36.4\% of predicted) and the forced vital capacity was 2.97 liters ( $80.1 \%$ of predicted). A flow-volume curve showed airflow limitation (Fig. 1). The residual volume was 2.57 liters ( $153 \%$ of predicted), the functional residual capacity was 3.97 liters (97\% of predicted) and the single-breath diffusing capacity of the lung for carbon monoxide $\left(\mathrm{DL}_{\mathrm{CO}}\right)$ and $\mathrm{DL}_{\mathrm{CO}}$ divided by alveolar volume ( $\left.\mathrm{DL}_{\mathrm{CO}} / \mathrm{VA}\right)$ were 105 and $93 \%$ of the predicted values, respectively. A chest radiograph showed scarce hyperinflation. No improvement in the $\mathrm{FEV}_{1.0}$ was observed following inhalation of a $\beta$-stimulant. A chest computed tomography (CT) scan showed only a small number of low-attenuation areas and bullae and demonstrated central bronchiectasis and a mosaic pattern, which intensified on expiration (Fig. 2). These findings were not consistent with pulmonary emphysema as a cause of severe airflow limitation. The results, including a respiratory function test and radiological examination, were highly suggestive of $\mathrm{OB}$. Inhalation of corticosteroid and anticholinergic agents, oral theophylline and inhaled corticosteroid were not effective in this patient. Respiratory rehabilitation and long-acting $\beta 2$-agonist/inhaled corticosteroid appeared to cause a slight reduction in his exertional dyspnea; however, the potential role of these therapies requires further examination. The patient did not recover completely. Twenty-six months following disease onset the patient remained alive and was discharged from the outpatient clinic.

\section{Discussion}

$\mathrm{OB}$ is an inflammatory process that primarily affects small conducting airways of the lungs, resulting in differing levels of airflow limitation (2). This inflammatory process is associated with numerous conditions, including UC (5-7), bullous skin disease (8), Stevens-Johnson syndrome (9-14), graft versus host disease following a lung or bone marrow transplant (15-18) and certain drugs $(1,6)$. The current patient was a middle-aged ex-smoker who complained of sub-acutely developed exertional dyspnea. Early-onset chronic obstructive pulmonary disease was initially suspected from the patient's symptoms and severe irreversible airway limitation; however, the chest CT scan was not consistent with smoking-induced centrilobular emphysema in this case, although the diagnosis of panlobular emphysema could not be refuted. It is generally accepted that decreases in $\mathrm{DL}_{\mathrm{CO}}$ and $\mathrm{DL}_{\mathrm{CO}} / \mathrm{VA}$ are useful indicators of pulmonary emphysema $(19,20)$; therefore, these parameters were evaluated, but no decreases were found despite severe irreversible airflow limitation. A mosaic pattern and bronchiectasis have been reported to be the typical findings in OB, although there have been cases demonstrating only diffuse hyperinflation, bronchial wall thickening and bronchiectasis, or even normal findings on a CT scan $(21,22)$. In the present patient, a chest CT scan showed bronchiectasis and thickening of the walls of the central bronchi in both lungs.

In the present case, the patient had UC and had received plasma exchange for the treatment of TEN, which are known causes of OB (1,4-6,23). TEN and Stevens-Johnson syndrome are defined as drug-related dermatopathies on the same spectrum (4), and a case of severe OB associated with TEN has been previously reported (24). We speculated that the $\mathrm{OB}$ in the present case may have developed as a result of an impairment of the respiratory mucous membrane, as observed in Stevens-Johnson syndrome, and that there was a high probability that this severe airflow limitation had an association with the development of TEN due to mesalazine therapy. Thus, if drugs were directly responsible for the development of $\mathrm{OB}$ in this patient, mesalazine would be a highly probable candidate.

Regarding adverse events due to mesalazine, certain pulmonary toxicities have already been reported $(5,6,25)$. Notably, two previous reports have described OB in patients with UC receiving mesalazine $(6,7)$, as observed in the present case; however, the cause and precise mechanism of $\mathrm{OB}$ resulting from mesalazine treatment is not currently known.

Pathological examination of the affected bronchioles is important to the diagnosis of OB $(1,26)$. The narrowing of 
bronchioles by necrotic and fibrotic changes are the main pathogeneses of $\mathrm{OB}(1,26)$; however, the majority of the patients with $\mathrm{OB}$ have exertional dyspnea with airflow limitation and it may, therefore, be challenging to obtain sufficient specimens from these individuals. The present patient declined a surgical approach, and the lung specimen could not be obtained.

In conclusion, the present study describes a case of OB in a patient with UC who developed TEN following mesalazine therapy. This rare clinical combination should be considered as a differential diagnosis, even for middle-aged, ex-smoking subjects presenting with sub-acutely developed airflow obstruction, if the findings in the chest CT scan demonstrate hyperinflation but few low-attenuation areas. Relatively well-preserved $\mathrm{DL}_{\mathrm{CO}}$ and $\mathrm{DL}_{\mathrm{CO}} / \mathrm{VA}$ can provide a clue to establishing a correct diagnosis.

\section{References}

1. Burgel PR, Bergeron A, de Blic J, et al: Small airways diseases, excluding asthma and COPD: An overview. Eur Respir Rev 22: 131-147, 2013.

2. Feuerstein JD and Cheifetz AS: Ulcerative colitis: Epidemiology, diagnosis, and management. Mayo Clin Proc 89: 1553-1563, 2014.

3. Mawson AR, Eriator I and Karre S: Stevens-Johnson syndrome and Toxic Epidermal Necrolysis (SJS/TEN): Could retinoids play a causative role? Med Sci Monit 21: 133-143, 2015.

4. Letko E, Papaliodis DN, Papaliodis GN, Daoud YJ, Ahmed AR and Foster CS: Stevens-Johnson syndrome and toxic epidermal necrolysis: A review of the literature. Ann Allergy Asthma Immunol 94: 419-436, 2005.

5. Nanayakkara PW, de Jong E and Postmus PE: Bilateral pulmonary infiltrates in a patient with ulcerative colitis receiving mesalazine. Eur J Intern Med 15: 470-472, 2004.

6. Haralambou G, Teirstein AS, Gil J and Present DH: Bronchiolitis obliterans in a patient with ulcerative colitis receiving mesalazine. Mt Sinai J Med 68: 384-388, 2001.

7. Sakamoto N, Ishimatsu Y, Koyama H, et al: Bronchiolitis in a patient with ulcerative colitis treated with erythromycin. Intern Med 53: 875-877, 2014.

8. Oshikawa K, Sugiyama Y and Kitamura S: Diffuse panbronchioliltis associated with bullous pemphigoid. Nihon Kyobu Shikkan Gakkai Zasshi 33: 1019-1023, 1995 (In Japanese).

9. Tsunoda N, Iwanaga T, Saito T, Kitamura S and Saito K: Rapidly progressive bronchiolitis obliterans associated with Stevens-Johnson syndrome. Chest 98: 243-245, 1990.

10. Shah AP, Xu H, Sime PJ and Trawick DR: Severe airflow obstruction and eosinophilic lung disease after Stevens-Johnson syndrome. Eur Respir J 28: 1276-1279, 2006.
11. Basker M, Cherian T and Raghupathy P: Chronic lung disease following Stevens-Johnson syndrome. Indian Pediatr 34: 831-835, 1997.

12. Yatsunami J, Nakanishi Y, Matsuki H, et al: Chronic bronchobronchiolitis obliterans associated with Stevens-Johnson syndrome. Intern Med 34: 772-775, 1995.

13. Reyes de la Rocha S, Leonard JC and Demetriou E: Potential permanent respiratory sequela of Stevens-Johnson syndrome in an adolescent. J Adolesc Health Care 6: 220-223, 1985.

14. Virant FS, Redding GJ and Novack AH: Multiple pulmonary complications in a patient with Stevens-Johnson syndrome. Clin Pediatr (Phila) 23: 412-414, 1984.

15. Ryu JH, Myers JL and Swensen SJ: Bronchiolar disorders. Am J Respir Crit Care Med 168: 1277-1292, 2003.

16. Epler GR: Bronchiolitis obliterans and airways obstruction associated with graft-versus-host disease. Clin Chest Med 9: 551-556, 1988.

17. Wyatt SE, Nunn P, Hows JM, et al: Airways obstruction associated with graft versus host disease after bone marrow transplantation. Thorax 39: 887-894, 1984.

18. Ralph DD, Springmeyer SC, Sullivan KM, Hackman RC, Storb $\mathrm{R}$ and Thomas ED: Rapidly progressive air-flow obstruction in marrow transplant recipients. Possible association between obliterative bronchiolitis and chronic graft-versus-host disease. Am Rev Respir Dis 129: 641-644, 1984.

19. Morrison NJ, Abboud RT, Ramadan F, et al: Comparison of single breath carbon monoxide diffusing capacity and pressure-volume curves in detecting emphysema. Am Rev Respir Dis 139: 1179-1187, 1989.

20. Biernacki W, Gould GA, Whyte KF and Flenley DC: Pulmonary hemodynamics, gas exchange and the severity of emphysema as assessed by quantitative CT scan in chronic bronchitis and emphysema. Am Rev Respir Dis 139: 1509-1515, 1989.

21. Tsujino I, Nishimura M, Ohira K, Yoshimura H, Fukuda Y and Kawakami Y: A case of idiopathic constrictive bronchiolitis in a middle-aged male smoker. Respirology 5: 305-307, 2000.

22. Karadag F, Ozhan MH, Akçiçek E, Günel O, Alper H and Veral A: Is it possible to detect ulcerative colitis-related respiratory syndrome early? Respirology 6: 341-346, 2001.

23. Ishida T, Yokoyama E, Muto M, et al: A case of paraneoplastic pemphigus associated with bronchiolitis obliterans-like respiratory symptoms in the absence of a known neoplasm. Nishi Nihon Hifuka 66, 236-240, 2004 (In Japanese).

24. Kamada N, Kinoshita K, Togawa Y, et al: Chronic pulmonary complications associated with toxic epidermal necrolysis: Report of a severe case with anti-Ro/SS-A and a review of the published work. J Dermatol 33: 616-622, 2006.

25. Kim JH, Lee JH, Koh ES, et al: Acute eosinophilic pneumonia related to a mesalazine suppository. Asia Pac Allergy 3: 136-139, 2013.

26. Allen TC: Pathology of small airways disease. Arch Pathol Lab Med 134: 702-718, 2010. 